\title{
MITOTIC AND MEIOTIC CHROMOSOMES OF A SOUTHERN BRAZILIAN POPULATION OF BOOPHILUS MICROPLUS (ACARI, IXODIDAE)
}

\author{
Rosane Nunes Garcia ${ }^{1}$ \\ Casemiro Garcia-Fernandez ${ }^{2}$ \\ Sonia Maria Lauer Garcia ${ }^{2}$ \\ Vera Lúcia S. Valente ${ }^{3}$
}

\begin{abstract}
Using conventional staining with acetic orcein and C-banding techniques it was investigated constitutive heterochromatin chromosomal polymorphisms and the mitotic and the meiotic behavior of male and female chromosomes of Boophilus microplus (Canestrini, 1887). Some differences were detected in the population of southern Brazil as compared to the data of other authors for populations in other latitudes. The differences being mainly concerned with the distribution of constitutive centromeric heterochromatin and variation in the length of heterochromatic blocks in the pericentromeric regions of some chromosome pairs.
\end{abstract}

KEYWORDS. Arachnida, Acari, chromosomes, C-banding, Boophilus.

\section{INTRODUCTION}

The only Boophilus species occurring in Brazil is Boophilus microplus (Canestrini, 1887), an Asian tick species which has been introduced into the majority of tropical and subtropical countries by the importation of Asian cattle. Infestation of cattle by the tick $B$. microplus results in economic damage due blood loss, transmission of Babesiosis and the serious damage caused to leather quality because of perforation of the hides during tick-feeding.

Cytogenetic studies have been conducted on several tick species, mainly concerning cytotaxonomy (KHAN, 1964) and the details of the meiotic events which occur during gametogenesis. OLIVER \& BREMNER (1968) described the chromosome number of male and female $B$. microplus, establishing the sexual determination mechanism (XX:X0) and the acrocentric nature of the chromosomes. Other tick, Ixodes ricinus Linné, 1758, have a $\mathrm{XX}: \mathrm{XY}$ type sexual determination mechanism in which the $\mathrm{Y}$ chromosome is very small, the mitotic metaphase $\mathrm{X}$ chromosome is invisible and a pair of chromosomes shows a

1. Instituto de Biociências, Universidade Federal do Rio Grande do Sul (UFRGS), Av.Bento Gonçalves, 9500, Bloco 4, 91501-970, Porto Alegre, RS, Brasil. (mshenz@terra.com.br)

2. Dept. de Ciências Morfológicas, Instituto de Ciências Básicas da Saúde, UFRGS, Rua Sarmento Leite 500, 90050-170, Porto Alegre, RS, Brasil.

3. Dept. de Genética, Instituto de Biociências, UFRGS, Av. Bento Gonçalves 9500, Bloco 3, Prédio 43323, Caixa Postal 15053, 91501-970, PortoAlegre, RS, Brasil. (vera.gaiesky@ufrgs.br) 
subterminal constriction in addition to the primary constriction (KAHN, 1964). These findings contradict the theory that an $\mathrm{XX}: \mathrm{XY}$ sexual determination mechanism is common to all soft ticks (Agarsidae) while all hard ticks (Ixodidae) have an XX:X0 mechanism. In both families males are the heterogametic sex and the sexual chromosome is, in general, larger than the autosomes (Oliver, 1965). The cytogenetic approach has also been applied to clarify the mechanisms involved in gamete formation during hybridization between related tick species. OLIVER \& BRINTON (1972) described the male reproductive apparatus of Dermacentor occidentalis Marx,1892 along with several stages of spermatogenesis but, other authors (NEWTON et al., 1972; GunN et al., 1993) have encountered difficulties in recognize prophase I in terms of the established Ixodidae pattern. The difficulties encountered in the interpretation of mitotic and meiotic patterns can be illustrated by the fact that very similar meiotic processes have been given different names in Hemophysalis leporis palustris Neumann, 1887 (KAHN, 1964) and Argas persicus Oken, 1818 (GoroshCHENKo, 1960), while the stage known as diakinesis in Boophilus annulatus Say, 1821 (Newton et al., 1972) spermatocytes has been interpreted by KAHN (1964) as Prophase II in Ixodes ricinus.

The similarity between the prophase II chromosome configurations of B. microplus and B. annulatus in Mexican Boophilus populations has been described by NewTON et al. (1972), who noted that male X chromosomes are 1.5 to 4 times larger than the maximum length of mitotic autosomes and that there were chromatin connections between $\mathrm{X}$ chromosomes in mitotic anaphases and the precocious migration of sexual chromosomes during meiotic metaphase I. Karyotypic variation in meiotic chromosome length has also been observed in Australian B. microplus populations by OLIVER \& BREMNER (1968), who stated that the male $\mathrm{X}$ chromosomes of these populations are 3 to 6 times larger than autosomes and the major autosomes twice the size of the minor autosomes. NEwTON et al. (1972) attributed these differences to technical problems, reporting that B. microplus and $B$. annulatus chromosomes gave indistinguishable karyotypes.

The southernmost Brazilian state, Rio Grande do Sul (RS), has a long history of cattle ranching which is important to the local economy. The uncertainly in the published research (carried out with $B$. microplus populations geographically distant from RS populations), the lack of information on karyotype configuration in B. microplus populations in RS, and the fact that the meiotic configuration of Boophilus females was unknown gave rise to characterize mitotic and meiotic chromosomal behavior in male and female B. microplus gonads. Thus, the aims was to investigate differences in the constitutive heterochromatin of the chromosomes of southern Brazilian B. microplus populations.

\section{MATERIAL AND METHODS}

Boophilus microplus ticks (10 adult males; 2 nymph males; 16 nymph females; 12 early engorged females) obtained from experimentally infested cattle reared in the Faculdade de Veterinária, UFRGS, Porto Alegre (30 $2^{\prime}$ $\mathrm{S}, 51^{\circ} 14^{\prime} \mathrm{W}$ ), Rio Grande do Sul, Brazil, were cytologically examined. Ticks were placed in Shen saline (containing $\left.(\mathrm{g} / \mathrm{l}) \mathrm{NaCl}, 9 ; \mathrm{KCl}, 0.42 ; \mathrm{CaCl}_{2}, 0.25\right)$ and dissected under a stereomicroscope, with the gonads being immediately transferred to a drop of $9 \%$ hypotonic sodium citrate solution placed on a glass slide which was then covered by a thin film of commercial gelatin and allowed to stand for $10 \mathrm{~min}$, after which they were fixed in 3:1 ethanol: acetic acid solution for $3 \mathrm{~min}$ and squashed in 3\% acetic orcein. The gonads of 8 females were C-banded using the method of GunN \& HiLBURN (1989) in which the barium hydroxide exposure time had been modified (1 min was found to be ideal) and stained with buffered Giemsa for $15 \mathrm{~min}$ and photomicrographs for cytological analysis were taken using a photomicroscope and 100 ASA film. Karyotypes were formed by placing the chromosomes in decreasing order size using the criteria of HILBURN et al. (1989). 


\section{RESULTS}

Mitosis was detected only in the nymphs of males and females (figs. 1-6) while different meiotic phases were only found in the gonads of adult males (figs. 7-14), although metaphases I, anaphase I and prophase II were not detect in the meiotic nuclei analyzed. Meiosis was not observed in the gonads of females. In two female nymphs it was possible to see bridges between the $\mathrm{X}$ chromosomes during mitotic anaphase (fig. 6), but no anomalous sexual chromosome migration was detected in any of the other mitotic cells analyzed.

No variation in B. microplus chromosomal number was found. In all the mitotic nuclei observed the X chromosomes were twice the length of the major autosomes (fig. 15), but this difference was not so pronounced in the meiotic nuclei (data not shown), where all X chromosomes appeared to be the same lenght as the autosomes. An extra-centromeric constriction was detected in autosome pair 3 (fig. 15).

The position of the centromere was not clearly defined by conventional staining, but C-banding showed both the acrocentric nature of the chromosomes and centromeric heterochromatic bands which appeared to be different among chromosomes, with chromosome pairs 4 and 6 containing large pericentromeric heterochromatic bands, while chromosome pairs 2, 5, 7, and 10 contain small heterochromatic bands. There were no heterochromatin polymorphisms between the individual chromosomes of each chromosome pair. Chromosome pairs were more easily recognized using C-banding and this allowed the construction of a schematic interpretation of the heterochromatin in the karyotype of $B$. microplus (fig. 16).

\section{DISCUSSION}

It was difficult to compare pictures of Boophilus microplus prophase I taken in the present study with those of different tick species and of those of B. microplus populations reported by other authors. This difficulty has already been reported in the Ixodidae by KAHN (1964) and Oliver et al. (1974). The configurations described by KAHN (1964) as prophase II and metaphase II in Ixodidae, were similar to those interpreted by us as telophase II. We recognize as anaphase II meiotic configurations similar to those described by NEWTON et al. (1972) as diakinesis. In the cytological material here examined it was relatively easy to see that the chromatids segregated individually, without terminal chiasmata, and that the degree of coiling was compatible with its stage (anaphase II). Meiotic metaphase I, anaphase I and prophase II were not detected, probably because they are very short stages. The lack of meiotic cells in the gonads of B. microplus females in the samples, confirms the results of several other studies performed on various tick species (OlIVER \& BRINTON, 1972; OlIVER et al., 1974; Oliver \& OSBURN, 1977; GunN et al., 1993).

In previous B. microplus studies, we also observed a relationship between the start of tick feeding and the amount of blood available to the tick and the start of cellular division, a relationship also reported in Otobius megnini (Duges, 1883) and O. lagophilus Cooley \& Kohls, 1940 by OLIVER \& OSBURN (1977). No cellular divisions were detected by us in B. microplus eggs and larvae in the period before the ticks were add to the host and were consequently without food. A decrease in the amount of cellular divisions (mitosis) was also observed in partially engorged females. Some results in the literature indicates that the process of oocyte maturation in the reproductive tract of females is 


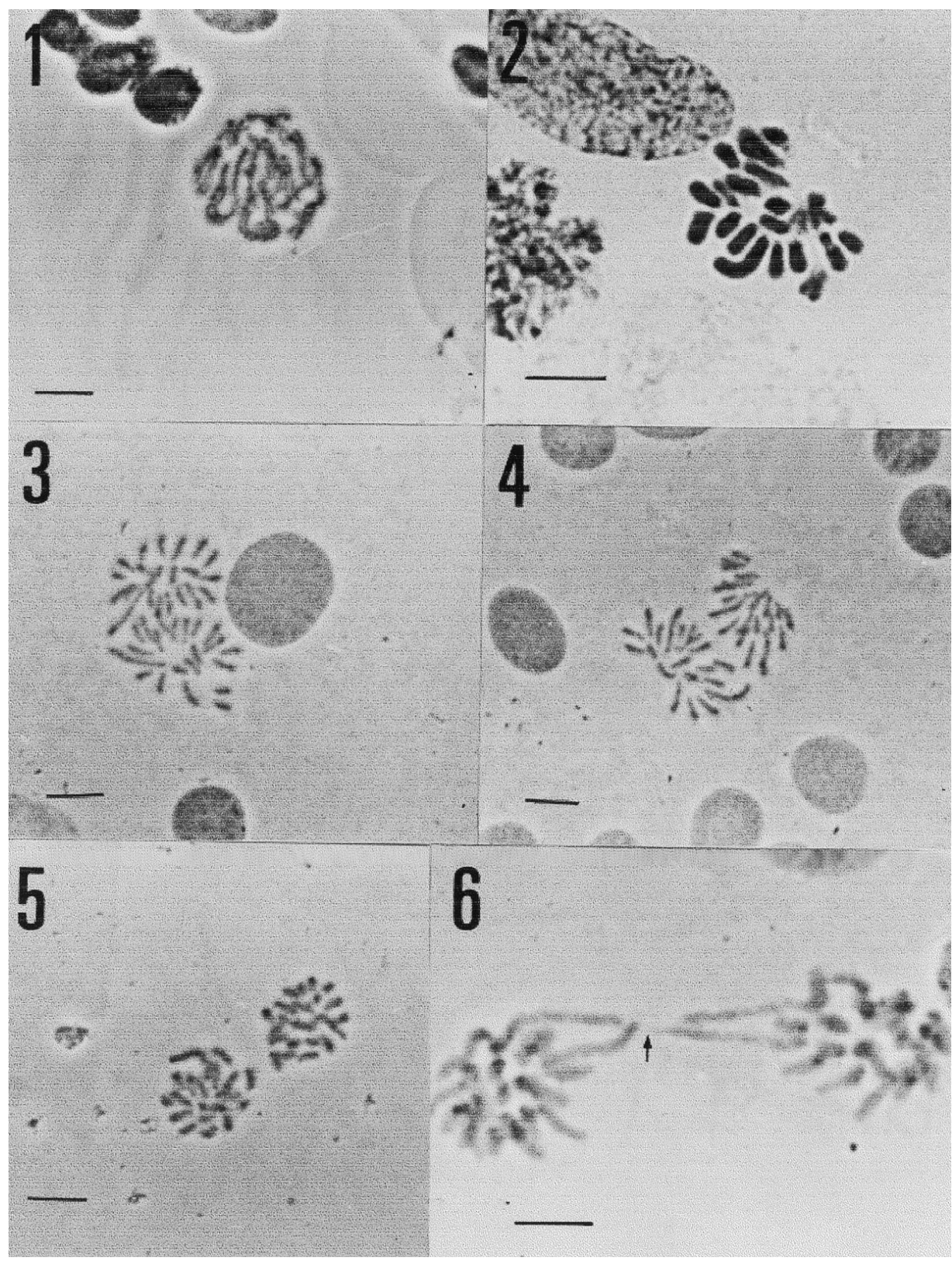

Figs. 1-6. The mitotic phases in the gonads of Boophilus microplus male and female nymphs (figs. 1-5, acetic orcein staining; fig. 6, C-banding). 1, late male prophase; 2, male metaphase; 3, initial male anaphase; 4, female anaphase; 5 , male telophase; 6 , female anaphase (the arrowhead indicates an X-chromosomes bridge). Bars, $0.01 \mathrm{~mm}$. 

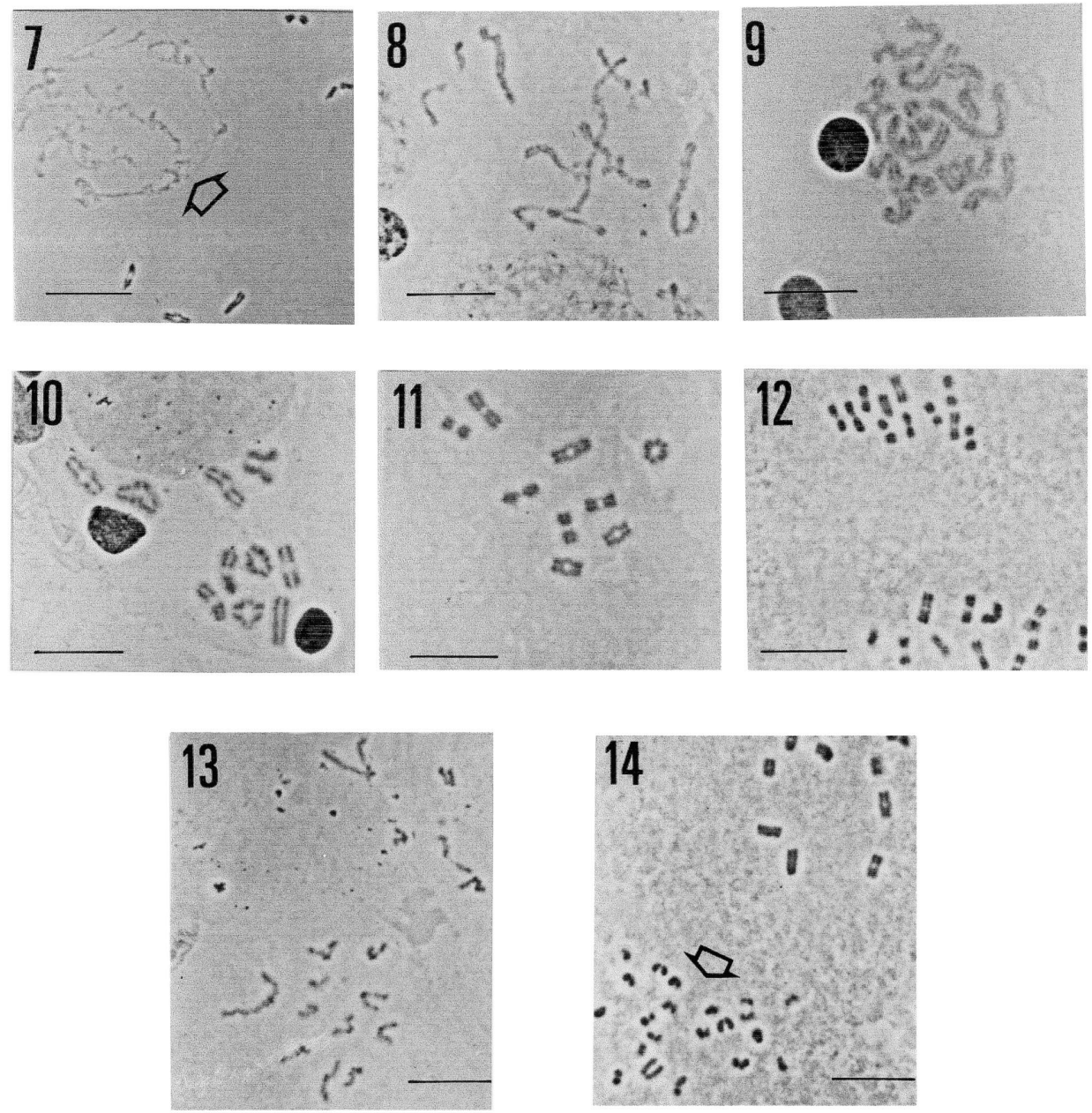

Figs. 7-14. The meiotic phases in the gonads of Boophilus microplus males (acetic orcein staining); 7, prophase I (arrow indicates pachytene); 8, prophase I (initial diplotene); 9, prophase I (diplotene); 10, prophase I (diakinesis); 11, prophase I (late diakinesis); 12, metaphase II; 13, initial anaphase II; 14, initial telophase II. Bars, $0.01 \mathrm{~mm}$. 


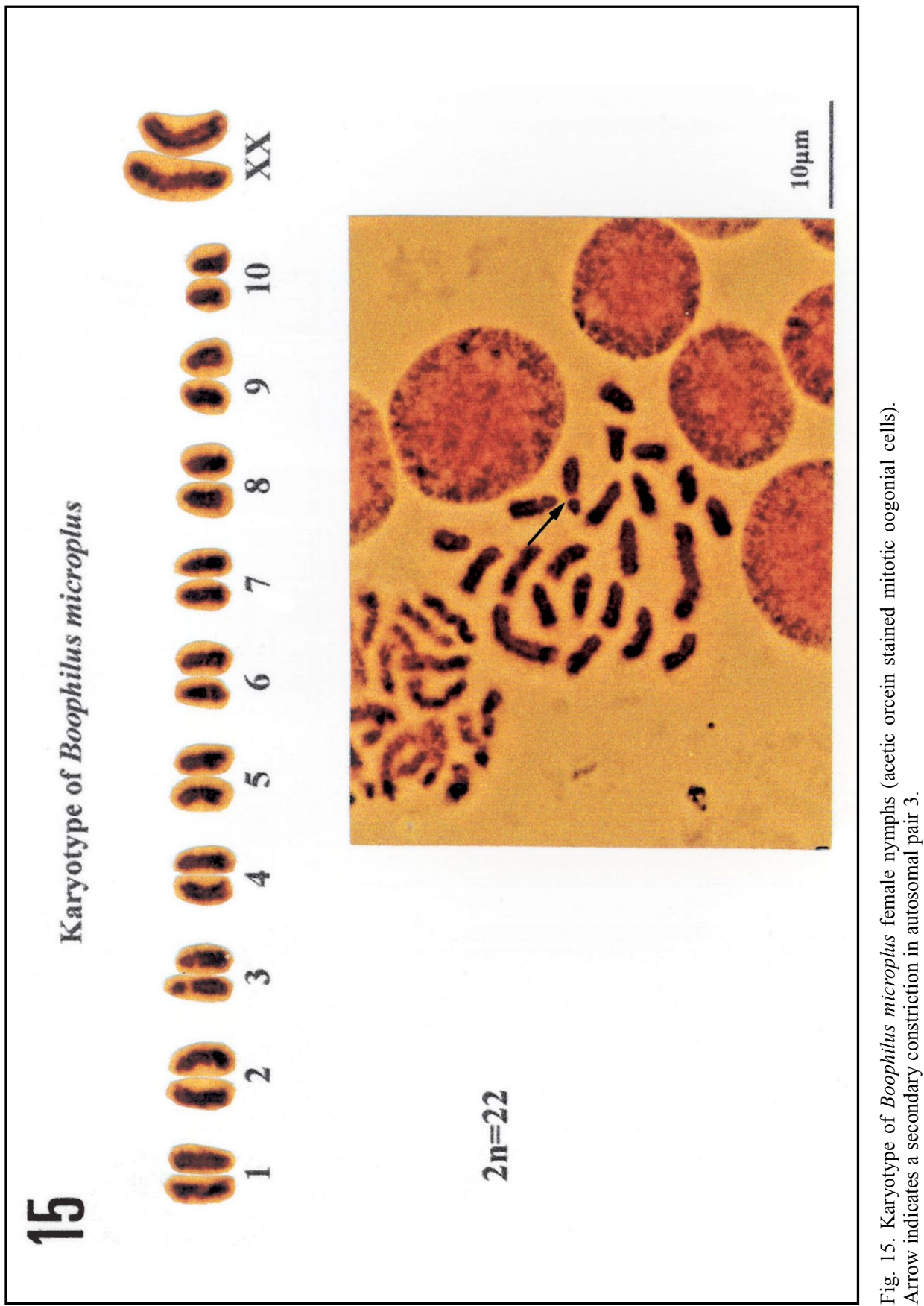




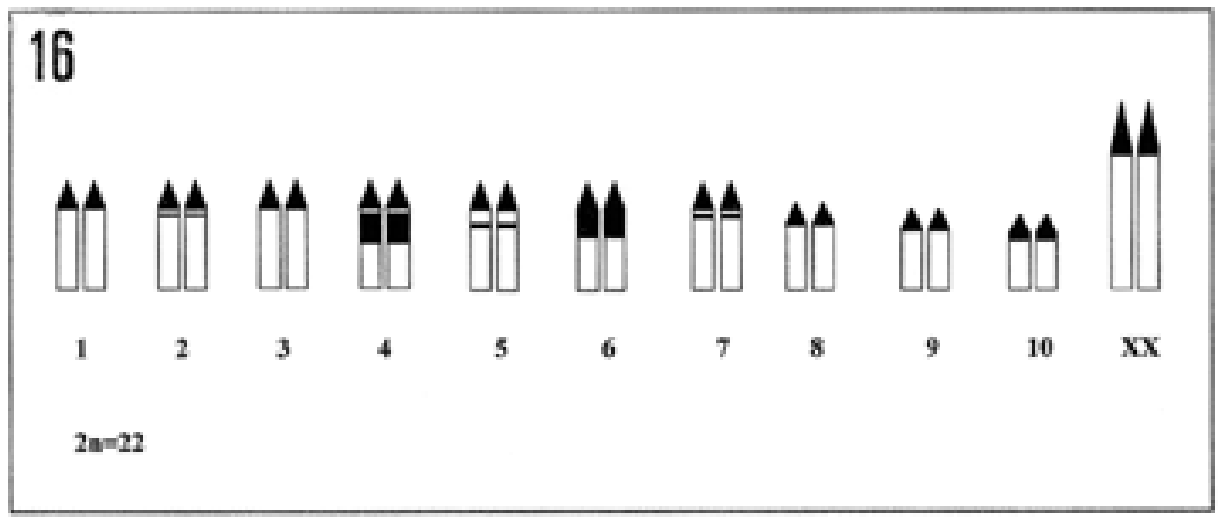

Fig. 16. Schematic C-banding pattern obtained for all Boophilus microplus chromosomal pairs. Dark areas correspond to positive C-bands in the centromeric (triangles) and pericentromeric (bars and rectangles) regions of the chromosomes.

complex (Garcia et al., 1993; Garcia-Fernandez et al., 1996) and is synchronized with the ticks general metabolism. OLIVER (1965) stated that the chromosome number of most Ixodidae ticks is $2 \mathrm{n}=21$ for males and $2 \mathrm{n}=22$ for females, in agreement with we found in southern Brazilian B. microplus population. These chromosome number were also reported by Newton et al. (1972) for Mexican populations and by HiLBURN et al. (1989) for southern USA populations.

Acetic orcein staining of mitotic chromosomes did not clearly detect the position of the centromere, something also noted in laboratory strains of Amblyomma cajennense Fabricius, 1787 (GUNN \& Hilburn, 1991). C-banding, however, allowed us to confirm that all B. microplus chromosomes are acrocentric, as suggested by OLIVER \& BREMNER (1968), a finding which suggests that no variation occurs in the chromosomal arrangements present in the southern Brazilian populations of B. microplus nor in those studied in different latitudes.

As was previously reported by Newton et al. (1972), we found little difference in length between meiotic autosomes themselves or between meiotic autosomes and Xchromosomes. Mitotic material allowed clearer differentiation of chromosomal pairs, and it was possible to observe that the larger autosomes were half of the length of the Xchromosomes. There was a secondary constriction in chromosome pair 3, as reported for one of the autosomes in Mexican B. microplus populations (HILBURN et al., 1989). The function of the anaphase bridges observed in mitotic X-chromosomes is not clear, although this phenomenon has been reported by NewTon et al. (1972) and apparently does not interfere with normal chromosomal segregation. This conclusion is reinforced by the fact that no supernumerary chromosomes were found in our material, something also noted by Oliver et al. (1974) in Acari. The fact that the same findings have been detected by different authors working with populations from very different geographical regions suggests that the world-wide $B$. microplus population is quite uniform with respect to karyotype general organization. 
The $\mathrm{C}$-banding enabled us to investigate novel aspects of $B$. microplus constitutive heterochromatin. In the southern Brazilian population studied several other C-bands were recorded besides those already described for other $B$. microplus populations by HILBURN et al. (1989), who described two small heterochromatin blocks in chromosomal pairs 2 and 10 and a larger one in chromosome pair 4. GunN et al. (1993) described a heterochromatin block in the centromeric region of the $\mathrm{X}$ chromosome. We encountered the same C-band pattern in all individuals analyzed, which allowed to discard the existence of intra-populational structural polymorphism. Several studies (JoHN \& KING, 1983; Kenton, 1991; ZhimULev, 1998) have reported the existence of polymorphism, which regard to the length and position of heterochromatic blocks between individuals of the same species as well as between individuals of related species.

Acknowledgments. To CNPq, FAPERGS, FINEP and PROPESQ-UFRGS for fellowships and grants.

\section{REFERENCES}

Garcia, S. M. L.; Garcia-Fernandez, C. \& Garcia, R. N. 1993. Modifications of the nucleus and nucleoli during the yolk formation in the thick Boophilus microplus Canestrini, 1887 (Acarina, Ixodidae). Revta bras. Biol., Rio de Janeiro, 55(1):74-84.

Garcia-Fernandez, C.; Garcia, S. M. L. \& Garcia, R. N. 1996. Histological aspects of the ovary during the process of vitelogenesis in Boophilus microplus (Acarina, Ixodidae). Iheringia, Sér. Zool., Porto Alegre, (80):47-54.

GoROSHCHENKO, Y. L. 1960. Structure of male gonads and peculiarities of spermatogenesis and oögenesis in Argasidae. In: GoRoschenko, Y. L. Problems of cytology and parasitology. Moscow, Akad. Nauk USSR. p. 222-233.

GunN, S. J. \& HiLbuRn, L. R. 1989. Differential staining of tick chromosomes: Techniques for C-banding and silverstaining and karyology of Rhipicephalus sanguineus (Latreille). J. Parasit., Lancaster, 75(2):239-245.

1991. Karyotypic variation in laboratory lines of Amblyomma cajennense. Aneuploidy and evidence of an autosomal translocation. J. Med. Ent., Honolulu, 28(3):350-356.

Gunn, S. J.; Hilburn, L. R. \& Burbach, B. S. 1993. Homology within they X chromosomes of Boophilus microplus (Canestrini) and Boophilus annulatus (Say). J. Hered., Washington, 84(3):232-235.

Hilburn, L. R.; GunN, S. J. \& Davey, R. B. 1989. The genetics of new world Boophilus microplus (Canestrini) and Boophilus annulatus (Say) in their possible control. Bull. Soc. Vector. Ecol., Santa Ana, 14(2):222-231.

John, B. \& KING, M. 1983. Population cytogenetics of Astractomorpha similis I. C band variation. Chromosoma, New York, 88:57-68.

Kahn, J. 1964. Cytotaxonomy of tick. Q. Jl microsc. Sci., Cambridge, 105(1):123-137.

Kenton, A. 1991. Heterochromatin accumulation, disposition and diversity in Gibasis karwinskyana (Commelinaceae). Chromosoma, New York, 100:467-478.

Newton, W. H.; Price, M. A. et al. 1972. Chromosome patterns in Mexican Boophilus annulatus and B. microplus. Ann. ent. Soc. Am., Madison, 65(2):508-512.

Oliver, J. H., JR. 1965. Cytogenetics of ticks (Acari: Ixodoidea) II. Multiple sex chromosomes. Chromosoma, New York, 17:323-327.

Oliver, J. R., JR. \& Bremner, K. C. 1968. Cytogenetics of tick. III. Chromosomes and sex determination in some Australian hard ticks (Ixodidae). Ann. ent. Soc. Am., Madison, 61:837-844.

Oliver, J. R., JR. \& BRINTON, L. P. 1972. Cytogenetics of tick (Acari: Ixodidae). 7. Spermatogenesis in the Pacific coast tick, Dermacentor occidentalis Marx (Ixodoidea). J. Parasit., Lancaster, 58:365-379.

Oliver, J. R., JR. \& OsbuRn, L. S. 1977. Cytogenetics of ticks (Acari: Ixodoidea). 15. Notes on chromosomes and maturation of Otobius megnini and O. lagophilus. J. Parasitol., Lancaster, 63:176-178.

Oliver, J. L., JR.; TANAKA, K. \& Sawada, M. 1974. Cytogenetics of ticks (Acari: Ixodoidea). 14. Chromosome of nine species of Asian haemophysalines. Chromosoma, New York, 45:445-456.

Zhimulev, E. 1998. Polytene chromosomes, heterochromatin and position effect variegation. In: Hall, J. C.; Friedmann, T. et al. Advances in Genetics. London, Academic. v. 37, p. 555-556.

Recebido em 18.01.2001; aceito em 20.10.200.1 